\title{
Covid-19 pandemic: a public and global mental health opportunity for social transformation?
}

\author{
Ayesha Ahmad lecturer in global health ${ }^{1}$, Christoph Mueller academic clinical lecturer in old age \\ psychiatry $^{2}$, Konstantinos Tsamakis consultant psychiatrist, research visitor ${ }^{2}$
}

${ }^{1}$ St George's University of London, London SW17 0RE, UK; ${ }^{2}$ King's College London, Institute of Psychiatry, Psychology, and Neuroscience, London, UK

We know from analysing conflict and post-conflict transitions that such crises can pose as an opportunity for social transformation. ${ }^{1}$ Given the humanitarian challenges of the ongoing pandemic, we think that covid-19 needs a public mental health focus. Covid-19 is the first major pandemic of our generation, ${ }^{2}$ and we must seek the hidden opportunities to reflect and react as a global society. From a collectivist perspective, we are given the same symptom checklist and the same prevention strategies regardless of where we are living in the world or our ethnic group, gender, age, or socioeconomic group. We have the chance to bring people of all cultures together and reduce prejudice and stigma because of the global nature of covid-19.

Covid-19 is challenging our position in the world because we realise our connectedness to those around us regardless of geographic distance, yet we are deeply aware of our individuality because the illness is a threat to our physical-and

mental-wellbeing. Our concepts, language, and understandings of our self and the world are merely semantics. We become our bodies through our experiences of illness. Covid-19 is as much a challenge of how we are going to frame it from a psychiatric perspective as it is a public health crisis. By merging public health with mental health, the ways that covid-19 are changing the world could be for better rather than worse. Our responsibility as mental healthcare professionals is to ensure that the ways we prescribe the meaning and representation of covid-19 to our own selves and the world enhances our mental health rather than limits what we can transform individually and globally.

Competing interests: None declared.

Full response at: https://www.bmj.com/content/368/bmj.m800/rr-13.

Yadav P. Social transformation in post-conflict Nepal: A gender perspective. Routledge, 201610.4324/9781315666037.

2 Razai MS, Doerholt K, Ladhani S, Oakeshott P. Coronavirus disease 2019 (covid-19): a guide for UK GPs. BMJ 2020;368:m800. 10.1136/bmj.m800 32144127

Published by the BMJ Publishing Group Limited. For permission to use (where not already granted under a licence) please go to http://group.bmj.com/group/rights-licensing/ permissions 